In the interest of prompt distribution, this LAMS report was not edited by the Technical Information staff.

This work was supported by the U. S. Atomic Energy Commission's Division of Safeguards and Security.

Printed in the United Staten of America. Available from

National Technical Information Service

U.S. Departmment of Commerce

5285 Port Rloyal Roud

Springlield, VA 2215!

Price: Printed Copy \$4.00 Microtiche \$2.25

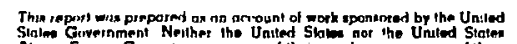

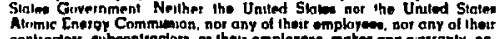

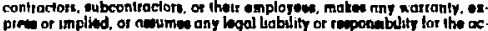

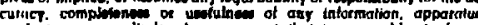

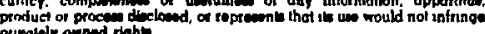




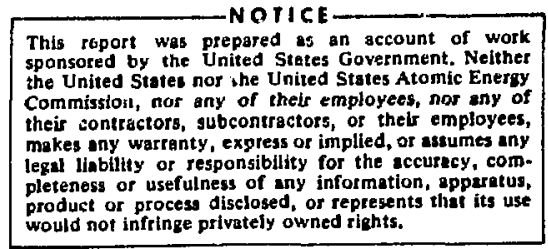

\title{
SUBROUTINES CALLABLE FROM PDP-11 BASIC FOR CONTROL OF A MULTICHANNEL PULSE-HEIGHT ANALYZER
}

by

Larry V. East

\begin{abstract}
A BSTRACT
A set of subroutines written to control a multichannel pulse-height analyzer interfaced to a PDP-11 minicomputer is described. These subroutines allow programs written in BASIC to perform all control and data transfer functions required to accumulate and analyze pulse-height spectra.
\end{abstract}

\section{I.}

\section{INTRODUCTION}

This report describes a set of subroutines that allow programs written in the BASIC language to perform data transfer and control functions on a multichannel p:ulse-height analyzer interfaced to a PDP-11 minicomputer. ${ }^{1}$ The pulse-height analyzer (PHA) is a Canberra Industries (Geoscience) Model 8700 with its own 4096-word memory. An interface ${ }^{2}$ between the PHA and computer allows the computer to control the analyzer functions (START, STOP, DISPLAY, etc.), test the status of the analyzer, and perform bidirectional data transfers between the analyzer and the computer. The "CAILL" statement available in the most recent version ${ }^{3}$ of BASIC for the PDP-11 is used to reference the subroutines that perform PHA control and data transfer functions. Two additional routines that control and read a programmable real-time clock $^{4}$ in the computer are included in the subroutine package.

Use of tise BASIC language allows users of the computer/PHA system to easily write and debug their own programs for on-line data acquisition and analysis. The language is easily learned and yet is powerful enough to easily handle the calculational operations required for pulse-height analysis.

\section{SUBROUTINE DESCRIPTIONS}

The subroutines available are summarized

in Table I. These routines are referenced by "CALL" statements of the form

CALL <stxing expression> (argument list) where <string expression> specifies the name of the subroutine (limited to four characters), and the argument list contains the input and output arguments required by the subroutine being referenced. The string expression is usually in the form of a literal string enclosed in quotes, but may also be a string variable. " The statement

CALL "PHAC"( $Z)$

is an example of the use of a literal string;

The subroutines described in this report are not intended for use with non-string versions of BASIC-11. 


\section{TABLE 1}

SUMMARY OF AVAILA BLE SUBROUTINES

Name and

Arguments

"MCAR" (I, X)

"MCAW"(I, X)

"ZERO"(I1, I2)

"SUM"(I1, I2, S)

PHAC"(X)

"PHAS"(X)

"BAND"( I1, I2)

"CLT"

"WAIT"

"ICLK"(X)

'CLK"(X)

LET X\$="MCAR"

CALL X\$ (N, Z)

is an example of the use of a string variable.

If the CALL statement does not have the proper syntax, i.e. missing quotation mark, parenthesis, comma, etc., the error message

SYNTAX ERROR AT LINE XXXX

will be issued, where " $\mathrm{XXXX}$ " is the line number in the BASIC program producing the error. If an argument is of the wrong type (string rather than numeric, for example), or not within the defined range, the error message

ARGUMENT ERROR AT LINE XXXX will be issued. Any attempt to address the PHA memory by the routines in Table I when the PHA "COMPUTER" switch is in the "DISABLE" position will cause the PHA to go to STOP mode and result in the error message

ADDR ERR AT LINE XXXX.

The following paragraphs describe in detail the subroutines, their arguments, and any additional error messages.

A. "MCAR" $(I, X)$

When this routine is called, the second argument, $X$, will be set equal to the contents of the PHA channel specified by the first argument, I. Both arguments must be numeric. The first argument must be within the range $0 \leq \operatorname{INT}(\mathrm{I}) \leq 4095$. and noninteger values will be truncated. Obviously, the second argument cannot be an expression or a constant.

B. "MCAW" $(\mathrm{I}, \mathrm{X})$

The PHA memory channel specified oy the first argument will be set equal to the integer part of the second argument. Both arguments must be numeric (constant, variable, or expressinn!. Acceptable values are $0 \leq \operatorname{INT}(\mathrm{I}) \leq 4095,0 \leq \mathrm{INT}(\mathrm{X})$ $\leq\left(2^{20}-1\right)$.

C. "ZERO"(I1, I2)

The contents of the PHA memory will be set equal to zero starting with the channel specified by the first argument thru the channel specified by the second argument. Both arguments must be numeric and in the range $0 \leq \operatorname{INT}(\mathrm{I}) \leq 4095$. and $\mathrm{II} \leq[2$.

D. "SUN:" (I1, 12, S)

The contents of the PHA memory starting at channel $I 1$ and ending at channel 12 will be summed and the result stored in $S$. The contents of the PIIA memory will not be altered. All three arguments must be numeric, and the third argument cannot be an expression or constant. The

\footnotetext{
This error message may also be issued if an atternpt is made to address a nonexistent computer memory location or I/O device register.
} 
first two arguments must be $0 \leq \operatorname{INT}(\mathrm{I}) \leq 4095$, with I1 $\leq$ I2.

E. "PHAC" $(\mathrm{X})$ or "PHAC"(X\$)

This routine will put the PHA into the operating mode specified by the argument, provided that the analyzer is computer enabled. If the PHA is not computer enabled, the PHA will be placed in STOP and the error message

PHA SETUP ERR AT LINE XXXX

will be issued. The argument may be either a numeric or string variable or expression. If it is a string, only the first three characters are significant. Acceptable argument values and resulting PHA modes are as follows:

$$
\begin{aligned}
& X=0 \text {, or } X \$=\text { "STO. . "; STOP mode. } \\
& X=2 \text {, or } X \$=\text { "DIS..."; DISPLAY mode. } \\
& X=3 \text {, or } X \$=\text { "COL..."; COLLEC } T \text { mode. }
\end{aligned}
$$

Any other argument value will result in the "ARGUMENT ERROR" message.

\section{F. "PHAS"(X) or "PHAS"(X\$)}

The argument, which may be either a numeric or string variable, will be set to reflect the current PHA operating mode. The possible returned values of the argument are:

$X=0$, or $X \$=$ "STOP" if PHA in STOP mode.

$X=1$, or $X \$=$ " $1 / 0$ " if $P H A$ in $1 / O$ mode.

$X=2$, or $X \$=$ "DISP" if DHA in DISPLAY mode.

$\mathrm{X}=3$, or $\mathrm{X} \$=$ "COLL" if PHA in COLLECT mode.

G. "BAND"(I1, I2)

The arguments, I1 and I2, which must be numeric variables, will be set equal to the values set in the lower and upper BAND thumb switches located on the PHA processor panel. If the lower BAND thumb switch setting is greater than 4095 . or greater than the upper BAND thumb switch setting, the error message

PHA SETUP ERR AT LINE XXXX

will be issued. If the upper BAND switch setting is greater than 4095, the second argument will be set equal to 4095 .

\section{H. "CLT"}

This routine resets the live/true time clock in the PHA. No argument is required or expected.
Note that the PHA clock cannot be reset by the "ZERO" routine.

I. "WAIT"

Calling this routine will interrupt the BASIC program until the PHA transfers to the STOP mode, either by manual intervention or by an automatic time-out during data collection. If the PHA is already in STOP when this routine is called, the BASIC program will immediately resume execution. Any "background" program that has been loaded with the RT-11 operating system version of BASIC will be executed while this routine is waiting for the PHA to stop. The reader is referred to Chapter 8 of the RT-11 BASIC manual ${ }^{3}$ for details on the use of a background program.

J. "ICLK" $(\mathrm{X})$

This routine will initialize (reset to zero) the real-time slock in the computer if the argument is 20 , and will disable the clock ${ }^{4}$ without resetting it if the argument is less than zero. Note that this routine has no effect on the PHA clock. The realtime clock must be initialized any time the computer has been halted and then restarted (either manually or by the power-fail/restart sequence), and any time that BASIC has been reentered from MONITOR.

K. "CLK"(X)

This routine sets the argument, which must be a numeric variable, equal to the time in seconds (to the nearest $0.1 \mathrm{~s}$ ) since the real-time clock in the computer was last initialized. The clock will overflow after approximately $466 \mathrm{~h}$.

\section{PROGRAMMING EXAMPLES}

T'wo short BASIC programs are presented below to illustrate the use of the PHA subroutine package. The first program puts the PHA through a data acquisition sequence and then performs a simple data analysis by summing the data over a group of channels selected by the BAND switches. Note that the single line

180 CALL "WAIT"

could have been used in place of lines 180 and 190 . 


\section{SAMPOL O1-OCT-74 EASIC Ye1-05}

19 REH SAHPLE BASIC PROGRFM USING PHF SUBROUHINE PACKAGE 190 LET K\$="GO"

110 PRINT "ENTER REGION OF INTEREST ON BAHD SWITCHES*

115 PRINT "TYPE = "GO"* WHEN REROY"

120 INPUT XE

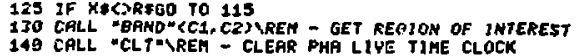

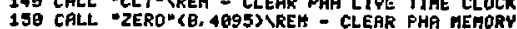

160 CALL

170 CALL ICLK"(1) IREH - IMITIRLIZE REAL TIME CLOCK

190 IF XDOUO TO 180 NREM - MAIT FOR PHA TO STOP

200 CALL "CLK"CT TREM - GET REPL TINE

210 CALL "PHAC"(2)IREH - PUT PHA INTO DISPLAY

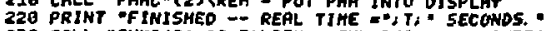

230 CALL "SUH" (C1, C2, 2 J SREH - SUH REOION OF IHTEREST

240 PRINT "SUM FROH CHANHEL", $\mathrm{Cl}^{\circ}$ " $\mathrm{TO}^{\circ}, \mathrm{C2}^{\circ}, 15^{\circ}, 2$

2SB CALL -PHAS- $(X E)$ YREM - OET PRESENT PHA STATUS

260 PRINT IFHA 15 HON IN 'S XF, HODE. -

270 LET RS" "YES

275 PRINT "DO IT ROAIM $P$

290 IF $X *-R \in C O$ TO 100

300 STOP

READY

RUN

ENTER REGION OF INTEREST ON BAHD SHITCHES

TYPE OD WHEN READY

TYPE

FINISHEO - REAL TIME - 11. 7 SECONOS.

SUI FROI CHANNEL 361 TO 380 is 49678

PHA 15 NOH IN DISP MODE.

DO IT AQAIN?

?HO

STOP AT LINE 300

READY

\section{Progran औ1}

The second program illustrates the use of "MCAR" and "MCAW" for data transfers between the PHA and computer. In this program, data from the PHA are read into a "virtual array" data file (a random access tape or disk file available with the RT-11 operating system version of BASIC-11) and then read back into the PHA from the file.
SAHPO2 01-OCT-74 BASIC VEL-65

40 REM BRSIC PROGRAM TO WRITE FHR CONTENTS INTO A -VIRTURL FRRAY* 19 REN BASIC PROG ANH THEN READ THE YIRTUAL RRRFY BFCK

20 REM INTO THE PHA MEMORY.

199 PRINT UTYPE FILE HAHE.

110 IMPUT RE

120 OPEN RE FOR DUTPUT AS FILE YF1<40SS

130 PRINT "FILE WILL BE WRITTEN MHEN PHA STOPS-

208 FOR $1=0$ TO 4095

230 CALL MCAR- $(1, x)$

220 LET VEI $I\}=\mathbb{X}$

230 NEKT I

310 CALL ZERO 40.4895

329 FOR $1=0$ TO 4095

336 CALL

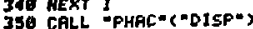

$37 \theta$ Cl.OSE VFI

400 stap

READY

RUN

TYPE FJLE NAME

PRILE GILL OE NRJTTEN HHEN PHA STOPS

STOP AT LIME 400

READY

Program "2

\section{REFERENCES}

1. Manufactured by the Digital Equipment Corporation, Maynard, Massachusetts.

2. Manuiactured by Canberra Industries, Meriden, Connecticut.

3. "BASIC/RT11 Language Reference Manual," Digital Equipment Corporation Marual DEC-11-LBACA-B-D (1973).

4. Obtained from Tennecomp Systems, Inc., Oak Ridge, Tennessee. The clock routines could easily be modified for use with a standard PDP- 11 programmable clock. 